calculation of settlements of larger foundations and this is demonstrated by an analytical study (Brown \& Gibson, 1979). This shows that the settlements are less than for the elastic half-space, by an amount that increases with the size of the foundation and with the rate of increase of stiffness with depth.

The modulus used in such calculations should be appropriate for the strain and time involved. The dependence on these variables is being studied and I believe that there may be a satisfactory mathematical model that will relate moduli measured under different conditions. Another dynamic method of measurements will be helpful.

\section{REFERENCES}

Brown, P. T. \& Gibson, R. E. (1979). Surface settlement of a finite elastic layer whose modulus increases linearly with depth. Int. J. Num. Anal. Meth. Geomech. 3, 37-47.

Burland, J. B., Sills, G. C. \& Gibson, R. E. (1973). A field and theoretical study of the influence of non-homogeneity on settlement. Proc. 8th Int. Conf. Soil Mech. Fdn Engng, Moscow. BRE Current Paper 32/73.

\title{
A one point cone penetrometer liquid limit test?
}

\author{
C. R. I. CLAYTON and A. W. JUKES (1978). Géotechnique 28, No. 4, 469-472
}

\section{D. Joyce, South Yorkshire County Council}

The test factors obtained by the Authors, and quoted in Table 1 for all soil, are virtually identical with figures obtained in South Yorkshire in 1977 even though the South Yorkshire figures were based on a sample size less than one fifth of that of the Authors and no doubt on different soils. It was also found that the reproducibility and accuracy of results using a one point cone penetrometer assessment were superior to those obtained by the one point Casagrande method. Of the liquid limits determined by the one point cone penetrometer test $94 \%$ fell within $\pm 2 \%$ of the four point test result. In view of the work that has now been carried out and the substantial cost benefits, I feel it would be appropriate for the British Standards Institution to consider the adoption of a one point cone penetrometer test and to investigate the possible use of the cone penetrometer in the determination of the plastic limit.

\section{A natural compression law for soils (an advance on $e-\log p^{\prime}$ )}

\author{
R. BUTTERFIELD (1979). Géotechnique 29, No. 4, 469-480
}

\section{Dr B. Schmidt, Parsons Brinckerhoff, San Francisco}

The Author expands elegantly on the traditional linear $e-\log p^{\prime}$ curves. Using natural strain rather than conventional strain straightens out nonlinearities often found at great strains, without greatly affecting stress-strain relations for small strains. The simplicity of the Author's concept is attractive, but the implication that it may be applied to a variety of soils, including perhaps granular soils, and to rebound and reload curves, requires further examination.

The example plots appear to show good straight-line relations for rebound and reload curves, although they are only slightly better than on standard plots. However, there are many examples of clay soils (e.g. Hansen \& Mise, 1964) showing rebound and reload curves that can be fitted only to far more complex mathematical expressions.

The relationship $d(\ln v)=-\mathbb{C} d\left(\ln p^{\prime}\right)$ works only when $m_{\mathrm{v}}=\mathbb{\Phi} / p^{\prime}$. For granular soils, this relationship does not work; here, another more general approach must be taken, such as that described by Janbu (1963). Janbu proposed a soil compression modulus that depends on stress level

$$
K=1 / m_{\mathrm{v}}=d p / d \varepsilon=c p^{1-s}
$$

For $s=1$, this is equivalent to Hooke's law; for $s=0$, it leads to

$$
d p / p=c d \varepsilon=-c d v / v
$$

